\title{
Debate
}

\section{Hepatitis B virus infected physicians and disclosure of transmission risks to patients: A critical analysis Diana L Barrigar ${ }^{1}$, David C Flagel 2 and Ross EG Upshur *3}

\begin{abstract}
Address: ${ }^{1 P G Y-1 ~ M c G i l l ~ U n i v e r s i t y, ~ F a c u l t y ~ o f ~ M e d i c i n e ~ M o n t r e a l, ~ Q u e b e c, ~ C a n a d a, ~}{ }^{2}$ Department of Humanities and Languages, Hazen Hall, Room 104, University of New Brunswick, Saint John, New Brunswick, E2L 4L5, Canada and 3Primary Care Research Unit, Sunnybrook and Women's College Health Sciences Centre, Assistant Professor, Department of Family and Community Medicine and Public Health Sciences and Joint Centre for Bioethics, University of Toronto, 2075 Bay view Avenue - A 100 Toronto, Ontario, M4N 3M5, Canada

E-mail: Diana L Barrigar - dianabarrigar@hotmail.com; David C Flagel - flagel@unbsj.ca; Ross EG Upshur* - rupshur@idirect.com *Corresponding author
\end{abstract}

Published: 25 October 2001

Received: 26 September 2001

BMC Medical Ethics 200I, 2:4

Accepted: 25 October 2001

This article is available from: http://www.biomedcentral.com//472-6939/2/4

(c) 200 I Barrigar et al; licensee BioMed Central Ltd. Verbatim copying and redistribution of this article are permitted in any medium for any non-commercial purpose, provided this notice is preserved along with the article's original URL. For commercial use, contact info@biomedcentral.com

\begin{abstract}
Background: The potential for transmission of blood-borne pathogens such as hepatitis $B$ virus from infected healthcare workers to patients is an important and difficult issue facing healthcare policymakers internationally. Law and policy on the subject is still in its infancy, and subject to a great degree of uncertainty and controversy. Policymakers have made few recommendations regarding the specifics of practice restriction for health care workers who are hepatitis $B$ seropositive. Generally, they have deferred this work to vaguely defined "expert panels" which will have the power to dictate the conditions under which infected health care workers may continue to practice.
\end{abstract}

Discussion: In this paper we use recent Canadian policy statements as a critical departure point to propose more specific recommendations regarding disclosure of transmission risks in a way that minimizes practice restriction of hepatitis B seropositive health care workers without compromising patient safety. The range of arguments proposed in the literature are critically examined from the perspective of ethical analysis.

Summary: A process for considering the ethical implications of the disclosure of the sero-status of health care workers is advanced that considers the varied perspectives of different stakeholders.

\section{Background}

The ethical issues surrounding health care workers infected with blood borne viruses and practice restrictions has drawn increasing attention. [1-15]. Many of the analyses have dealt exclusively or at least significantly with the issue of disclosure of seropositivity as a means for infected HCWs to continue to practice [3-9]. However, most have focussed on HIV and have not adequately addressed the unique features of HBV, particularly its pre- ventability and higher transmissibility, which distinguish it from HIV.

Of the few papers which have focused on HBV-infected HCWs, none have adequately addressed the issue of disclosure of seropositivity as a means for infected HCWs to continue to practise. Ristinen and Mamtani advocate disclosure of seropositivity as a means of allowing patients to participate in care, however, their discussion is quite superficial and does not address all of the primary 
stakeholders in the issue [2]. Blatchford et al discuss an actual case of an HBV-infected dentist, and the results of a survey of exposed patients. They also advocate disclosure of seropositivity, but argue this primarily from the patient's right to know perspective and do not address the issues from the HCW's perspective [4].

Thus, what appears to be missing from the literature is a comprehensive examination of disclosure of HCW seropositivity and its role in determining appropriate practice restrictions for $\mathrm{HCWs}$ infected with hepatitis B virus. In this paper we review the arguments from the literature, including the interests of the at-risk patient, the infected HCW, and the health care system. We attempt to provide a comprehensive and practical approach to including disclosure of seropositivity in a system of practice restriction for HBV-infected HCWs.

\section{Epidemiology of HBV transmission}

HBV is transmitted by percutaneous or permucosal exposure to infectious body fluids, by sexual contact with an infected person, and perinatally from an infected mother to her infant [16]. It differs from other transmissible pathogens in several important ways. First, it is more highly transmissible than HIV or hepatitis $\mathrm{C}$ virus (HCV). In fact, HBV may be transmitted from HCWs to the patient despite full compliance with universal precautions and correct infection control procedures [17]. An estimated 240 to 2,400 transmissions occur per million procedures by an $\mathrm{HBV}$-infected HCW compared to 2.4 to 24 per million transmission rate by an HIV-infected HCW [17]. Chronic carrier status is identified serologically by a positive hepatitis B "surface" antigen (HBsAg) titre. Although it was once thought that only individuals testing positive for hepatitis B "envelope" antigen (HBeAg) in addition to HBsAg were at risk of transmitting the infection, it is now known that surgeons who are carriers of $\mathrm{HBV}$ without detectable levels of serum HBeAg can transmit HBV to patients during procedures [18]. Seroconversion rates after exposure to the virus in a non-immunized individual range from $19-30 \%$ if the source person is $\mathrm{HBeAg}$ positive and $5 \%$ if the source person is $\mathrm{HBeAg}$ negative [17].

In terms of prevalence of HBV infection among HCWs, data from the most recent U.S. National Health and Nutrition Examination (NHANES) did not show an increased prevalence of chronic $\mathrm{HBV}$ infection among adults with a medical occupation as compared to the rest of the sample. However the NHANES study did not separate out specialities within medicine, e.g. surgeons, where there may be a higher prevalence of HBV infection. This study estimated a prevalence of $\mathrm{HBV}$ infection in the U.S. population of 5.5\%, with $0.33 \%$ being chronically infected, in the period between 1976 and 1980 com- pared to $4.9 \%$, with $0.42 \%$ being chronically infected, between 1988 and 1994[19].

Besides its high transmissibility relative to $\mathrm{HCV}$ and HIV, HBV also differs in its preventability by immunization. In Canada, this consists of 3 intramuscular doses of a recombinant vaccine, administered in a series of 3 injections over 6 months (at o, 1 and 6 months), with a 9599\% protective immune response observed among pediatric and young adult populations [20]. Immune response to the vaccine series is lower in adults over age 40 and immunocompromised individuals [20]. Fractionated anti-HBs immunoglobulin (HBIG) is often used in combination with the vaccine series for post-exposure prophylaxis, however, there is no consensus as to how much additional protection, if any, it offers [16].

It is also important to know that hepatitis B is endemic to many developing countries. The vast majority of chronic carriers worldwide are individuals who were born in areas of high endemicity (i.e., where $\geq 8 \%$ of the population is $\mathrm{HBsAg}$-positive) and who contracted the virus during early childhood or perinatally, i.e., via vertical transmission from mother to neonate [21]. For example, in East Asian, Southeast Asian and Pacific Island countries, 35 to $50 \%$ of $\mathrm{HBsAg}$-positive women are also $\mathrm{HBeAg}$-positive. If a mother is $\mathrm{HBeAg}$-positive, her infants have a 70 to $90 \%$ risk of becoming infected if they do not receive immunoprophylaxis at birth, which is not routinely available in most countries where the virus is endemic. Forty-five per cent of the world's population live in areas of high endemicity which include Africa, most of Asia (except Japan and India), most Pacific Island groups, most of the Middle East, the Amazon Basin of South America, and areas inhabited by special populations such as native Alaskans, Australian aborigines, and New Zealand Maoris [21].

In summary, HBV differs from other transmissible pathogens such as hepatitis C and HIV by virtue of its higher transmissibility, its preventability, and its endemicity to many developing countries.

\section{Current policy on practice restrictions for HBV- infected health care workers}

The Laboratory Centre for Disease Control (LCDC) of Health Canada recently issued recommendations for health care institutions and individual HCWs regarding transmission of bloodborne pathogens to patients by infected HCWs [17]. The recommendations are advisory in nature but represent one of the most authoritative sources of guidance for Canadian physicians and their provincial/regional licensing bodies. We will be focusing on the recommendations regarding disclosure of risks to patients, but we will briefly outline the LCDC approach to- 
ward practice restrictions as this will provide the context for the disclosure recommendations.

According to the LCDC recommendations, HCWs and student HCWs who perform or will perform "exposureprone procedures" and who test positive for HBsAg should be referred to an expert panel for assessment. If they are HBeAg positive, they should also cease practice immediately, whereas those who are $\mathrm{HBeAg}$ negative may continue to practise pending the panel's assessment. Those who refuse screening are presumed HBeAg positive and treated as such. The expert panels are to be established by the provincial and territorial regulatory bodies, and are responsible for addressing the issue of whether the HCW is safe to continue practising exposure-prone procedures. The LCDC advises the expert panel to consider factors such as the type of infection and viral load; procedural techniques; skill and experience of the HCW; evidence of prior transmission by the HCW; the HCW's compliance with universal precautions and other infection control practices; and the likelihood of compliance with the practice recommendations. From this list, it appears as if the LCDC expects the panel primarily to perform a harm-benefit analysis based on the individual circumstances. LCDC also recommends that "relevant ethical principles" be considered in the decision making, but fails to provide further guidance in this area.

The LCDC guidelines also address the protection of HCW privacy and confidentiality. In the case of physicians, their recommendations stipulate that the professional regulating body be notified of the seropositivity of any practising physician, and that others, including members of the expert panel who will be making practice recommendations, should be given personal health information "strictly on a "need to know' basis." Similarly, the LCDC recommended steps to protect the infected physician's identity when disclosure to patients was considered.

Since disclosure to patients is the focus of this paper, we have provided the LCDC recommendations on disclosure in full:

"1. Provided that the infected HCWs health status and the exposure-prone procedures have been assessed by the expert panel and all the panel's recommendations are followed, disclosure of a HCWs infected status to patients before an exposure-prone procedure is carried out is not required as a way of protecting patients from blood-borne pathogens.

2. After a significant exposure from any HCW has occurred, the patient must be notified that he/she was ex- posed to the blood of a member of the HCW team (the HCW does not need to be identified by name).

3. The HCW has an obligation to be tested following a significant exposure to the patient. If the HCW tests positive for HBV, HCV or HIV the patient has the right to know to which pathogen he/she was exposed in order to access the appropriate post-exposure protocol."

It is worthwhile knowing the policy positions of other professional associations in order to serve as a comparison to the LCDC recommendations on practice restriction and disclosure to patients. The Canadian Medical Association (CMA) policy recommends that "physicians who test positive for HBsAg cease activities of their practice that could expose patients to their body fluids until their practice has been reviewed by an expert committee" [22]. In terms of practice restriction, the final decisions are left up to the expert committee, but the CMA offers some guidance for achieving this. In particular, the CMA recommends if HBV infectivity could not be reduced to "acceptable levels", the physician's practice should be restricted by directing the physician.

"to practise only on immune or infected patients when his or her body fluids could come into contact with those of the patient; and in the event the patient's immune status is unknown, not to practise specified procedures during which his or her body fluids could intermingle with those of the patient"[22].

The CMA does not define what it considers "acceptable levels" of infectivity. For comparison sake, the U.S. Centre for Disease Control (CDC) issued recommendations in 1991 which differ from the LCDC recommendations on the topic of disclosure to patients [23]. These recommendations stated that

"HCWs who are infected with HIV or HBV (and are HBeAg positive) should not perform exposure-prone procedures unless they have sought counsel from an expert review panel and been advised under what circumstances, if any, they may continue to perform these procedures. Such circumstances would include notifying prospective patients of the HCW's seropositivity before they undergo exposure-prone invasive procedures."

These CDC guidelines have been subject to much criticism, and we will be examining those critiques before recommending a policy regarding practice restriction and disclosure of seropositivity which could be applied to either U.S. or Canadian health care systems 


\section{Discussion \\ Ethical problems with the LCDC recommendations on dis- closure to patients}

It is worthwhile pointing out some concerns with the LCDC's general approach to practice restrictions. First, the current recommendations leave too much discretion in the hands of the elusive expert panels. More detailed guidelines with regard to practice restriction would do more to ensure that infected HCWs are treated according to a fair process, and are not as vulnerable to the particular biases and experiences of the members of the expert panel overseeing their case. As well, a New Jersey court case involving a surgeon with AIDS drew attention to the conflict of interest of colleagues sitting on such a committee [3]. Their judgement may be influenced by fears of becoming infected themselves at some point in their career.

As for the LCDC recommendations on disclosure of risks to patients, they fall short of current legal requirements for informed consent and have some other ethical drawbacks as well. In terms of an ethical analysis of these disclosure recommendations, there are three parties whose interests we must keep in mind: the infected HCW's interests in keeping his/her career and in performing his/ her role to improve the health of patients, the patient's interest in not contracting a potentially fatal infection, and society's interest in maintaining an effective and affordable health care system. This involves addressing ethical arguments such as the HCW's right to privacy, the HCW's right to freedom from discrimination, the duty of HCWs to provide benefit for their patients and not do them harm, and the patient's right to autonomy and informed choice. In addition, the societal benefits and/or burdens of any policy should also be considered. Any policy recommendations should also be legally prudent.

\section{The case for disclosure of serological status}

The process of informed choice and its legal requirements have evolved with the purpose of enhancing and protecting patient autonomy in medical decision-making. Failure of physicians to disclose "material, special or unusual risks" regarding a medical treatment or procedure to which a patient consents may result in a battery or negligence suit against the physician [3,7,24]. Risks meriting disclosure are determined in Canadian courts by what a "reasonable person in the patient's position" would want to know in order to decide whether or not to undergo a procedure. Risks of $1 \%$ or less have been deemed "material" by Canadian courts if the consequences are adequately serious that a reasonable person in the patient's position would want to know those risks before consenting to a procedure $[7,24]$.
With regards to blood-borne pathogens in particular, an Ontario court held that the risk (described in evidence as "infinitesimally small') of contracting hepatitis through a blood transfusion ought to have been disclosed in a 1989 case $[7,24]$. The risk of contracting $\mathrm{HBV}$ via an invasive procedure when the serological status of the HCWs involved is unknown can be calculated by multiplying the prevalence of chronic $\mathrm{HBV}$ infection (0.42\%) with the risk of transmission (240-2,400 per million). This results in a transmission risk of between 1 and 10 per million. Although very small, this risk is that of acquiring a potentially fatal disease, and as such it would be very difficult to argue that it should not be disclosed to patients. The manner of disclosing this risk will vary with each individual and it is difficult to know if a blanket statement commonly used by HCWs such as "there is a 1\% risk of infection from this procedure" is adequate, or whether they ought to specify the source of the infection. Acquiring $\mathrm{HBV}$ as a result of an invasive procedure is certainly a qualitatively different outcome than having one's recovery complicated by a superficial wound infection.

The more difficult question is whether HCWs who are known to be HBV-seropositive ought to disclose their serological status to patients prior to procedures. This changes the risk of transmission from between 1 and 10 per million to between 240 and 2,400 per million. This represents a 200-fold increase in risk but the absolute risk is still less than one per cent. Disclosure of this increased risk would enhance patient autonomy by allowing individual patients to decide whether or not to have a procedure performed by an infected HCW based on the significance of the infection risk to the patient. For many patients, e.g., a young patient undergoing a common and widely available procedure, this risk will likely be considered very significant and they probably will choose to have the procedure performed by someone else. Alternatively, consider a terminally ill patient undergoing a palliative procedure, for whom the risk of acquiring a bloodborne pathogen with primarily long-term complications may not be particularly significant. It may be more important, for example, for such a patient to have the procedure performed as soon as possible by an HCW with whom they have a long-standing and trusting relationship. These two scenarios are illustrative of the different values patients may have, and offering patients the choice of having a procedure performed by a known infected HCW allows them to make a decision based on their individual values and priorities.

Such an approach is legally prudent as well. In 1993 the Maryland Court of Appeals, using a "reasonable patient" disclosure standard similar to Canada's, ruled that a surgeon who was HIV seropositive did have a duty to warn patients of his/her infected condition or refrain from op- 
erating upon them [7]. The ruling also stipulated patients could recover damages for their fear of acquiring AIDS for the period of time between learning of the surgeon's seropositive status and receiving HIV-negative results. With the higher transmission rate of HBV by an infected HCW to a patient, it is likely that courts would require the same duty of HBV-seropositive HCWs.

Further, a 1991 Newsweek poll reported that 95\% of the American public wanted surgeons to be required by law to tell their patients if they are HIV-infected $[7,15]$. Ninety-four percent wanted disclosure from physicians and dentists, and 90\% wanted disclosure from all HCWs. Thus, the seropositive status of HCWs and the risk it poses to patients is something that "reasonable" patients want to know.

Thus, from the perspectives of promoting patient autonomy and doing what is legally prudent, there are very strong cases in favour of infected HCWs disclosing their serological status to patients as a requirement of performing invasive procedures. However, there are ethical challenges to such a disclosure policy which need to be addressed. These come from two different camps - those who argue that disclosure in and of itself is not sufficient for protecting patients from significant transmission risks and those who argue disclosure should not be required for infected physicians to continue to practise. We will examine these arguments in turn.

\section{The duty of health care workers to benefit their patients and do them no harm}

All physicians and most other health care workers will at some time in their life have heard the potent expression "primum non nocere", which translated means "above all, do no harm." This phrase is often quoted, but as Beauchamp \& Childress acknowledge, "its origins are obscure and its implications unclear."[25] However, it provides the foundation for the ethical principle of nonmaleficience, which "asserts an obligation not to inflict harm intentionally"[25].

In this vein, Tereskerz et al. argue that infected HCWs not perform any procedures which present a risk of transmission of blood-borne pathogens to patients and that there be national policy involving lists of procedures which health care workers with specific infections should refrain from performing [3]. They do not consider disclosure of transmission risk to patients an adequate measure for protecting patients, however they acknowledge it to be a useful temporary measure to provide "limited" protection for patients until a more ideal national policy regarding practice restriction is put in place. They argue that "patients may find it difficult to evaluate scientific information concerning risk and may be reluctant to re- quest an alternative physician when their own physician is infected"[3]. Thus, on the basis of preventing patients from harm, they propose quite strict practice restrictions which would vary according to the specific pathogen with which the health care worker was infected and the specific procedures to be performed.

While their proposal is noteworthy for its interest in protecting patients from harm, it may be overly paternalistic when considering disclosure. Instead of allowing patients to determine for themselves what degree of risk they are willing to accept, an expert committee would decide what level of risk is acceptable to patients in the course of deciding which procedures an infected HCW may perform.

There are also other methods of preventing HBV transmission which may be implemented instead of, or in addition to, practice restrictions. For example, surgical patients could be offered immunization prior to elective invasive procedures. This would have the added benefit of protecting them from contracting HBV via other modes of transmission, e.g. sexual contact or IV drug use. Current costs of serological tests and vaccinations may be considered prohibitive factors, but there are enough proponents of universal $\mathrm{HBV}$ vaccination that these costs should not be difficult to justify. HBV vaccination is currently funded by provincial ministries of health as part of child immunization programs (either as infants or at 12 years of age), and is also offered by public health units to individuals in high risk populations. Providing $\mathrm{HBV}$ vaccination routinely to surgical patients would simply be an extension of a pre-existing public health program.

It is also worth considering the HCW's own interests in avoiding harm to their patients. Although there are certainly other benefits to be gained from a career in health care, the majority of HCWs are at least partially attracted to their profession by the desire to help people by improving their health, well-being and/or quality of life. Certainly most HCWs would feel at least some degree of remorse if they learned they had transmitted HBV to one of their patients. Surely, they would also want to avoid the legal difficulties which would ensue.

In addition to the duties to provide benefit and do no harm to patients, another important role of the HCW is that of educator. Health care workers are generally regarded with respect by patients and often have the opportunity to serve as societal role models. If an HCW were to reveal his/her own seropositivity in a positive manner, this could help reduce the stigmas and fears associated with HBV and other infectious diseases. 
In summary, the combination of disclosing seropositivity and offering vaccination to patients undergoing invasive procedures sufficiently minimizes the harm to patients to make this approach both ethically and legally acceptable in terms of protecting patients' interests. It would also contribute to the role of the HCW as healer and educator. However, other important interests of health care workers such as their right to privacy and freedom from discrimination have yet to be addressed.

\section{The discriminatory nature of a disclosure of serological status policy}

Several authors have argued that infected HCWs should not be discriminated against on the basis of their infective status $[1,5,7,26]$. Pinching is wary of restricting the practice of infected HCWs, and points out "those professionals whose work puts them at most risk from bloodborne infections from their patients are in effect regarded as having lesser health rights if potential transmission goes the other way"[26]. Norman Daniels considers the conflict between patients' and HCWs' perceptions of risks and discusses the distinction between objective and subjective risk. On the one hand, he points out that patients' perceptions of transmission risks are likely to be exaggerated, but respecting a patient's right to choose which risks they will accept for themselves suggests we accept patients' subjective perceptions of transmission risks. "In contrast," he writes "the insistence on protecting the rights of handicapped workers is intended to protect them against the exaggerated or fabricated perceptions of fellow workers and employers; the tendency is to insist that the significance of the risks they impose on others be objectively determined [5]." Indeed it is this tension between patients' and HCWs' interests which is at the heart of this debate.

In Canada, legal protection against discrimination on the basis of a "handicap" can be derived from the Charter of Rights and Freedoms, the Canadian Human Rights Act, and the provincial Human Rights Codes [7]. The provincial codes are probably most important in this debate, since they cover matters within provincial jurisdiction, which includes most health care settings. Since at least 1992 the Ontario Human Rights Commission has interpreted protection against discrimination to extend to all persons infected with HIV, including those who are asymptomatic [7]. Flanagan summarizes the protection from discrimination of HIV-infected workers under the Ontario Human Rights Code as being legally binding unless

"1) the infected worker is reasonably likely to pose a serious risk to the health and safety of her patients; 2) this risk is not similar to the other types of risks that are associated with the delivery of health care and generally tolerated in society; and 3) even after accommodation the remaining risk to the health or safety of her patients outweighs the benefits of enhancing equality for the HIV-infected HCW"[7].

Flanagan thus argues that although there is some risk associated with HIV-infected HCWs continuing to practice, this risk is extremely small and within the range of risks society has long tolerated in the delivery of health care.

Daniels and Gostin draw similar conclusions. However, all authors were considering primarily the case of HIVinfected HCWs. Does the 100-fold greater transmission risk for HBV change their conclusions? Daniels quotes risks of death due to general anaesthesia as 10 per million, which by his data was 10 times greater than the risk of being infected by a surgeon known to have HIV infection, but by newer data (2.4 to 24 per million) is roughly equivalent. More importantly, what these authors do not acknowledge is that routinely acceptable risks, such as the risk of dying from anaesthetic use, are still disclosed to patients even though the vast majority of patients are willing to accept these risks. There will always be the rare patient who will refuse surgical procedures with a high cure rate because of their unwillingness to accept the low risks of anaesthetic and surgical complications. Therefore, this is not a good argument for not disclosing transmission risks, especially since $\mathrm{HBV}$ is 100 times more transmissible than HIV.

It should also be acknowledged that many HCWs who are chronic carriers of HBV acquired the disease by virtue of being born or spending their early childhood in a region of the world with high prevalence of the virus. Thus, restricting the practice of these HCWs represents a degree of discrimination against people from certain regions of the world or from special populations, such as aboriginal groups. Barring entry to professional educational programs on the basis of HBV seropositivity provokes similar ethical debates, although they are beyond the scope of this paper. Once again, the risks to patients and coworkers need to be weighed against the negative effects to the individual and the population group from which he/she comes. Clearly, a policy which minimizes practice restrictions for these HCWs without compromising patient safety is preferable to a more restrictive policy.

\section{Privacy argument}

Several authors consider another argument, which is that the serological status of an infected HCW is information which need not be disclosed to the patient because it is private information about the HCW $[1,5,7]$. They consider other factors affecting physician perform- 
ance such as stress, fatigue, medication side effects, family problems, legal disputes, etc. which may affect physician performance and cause harm to patients to the same degree as representing a transmission risk of a blood-borne pathogen. Do patients have a right to know this type of private information about HCWs which might affect their consent decision? What about other private information such as the HCW's performance on exams, history of malpractice suits, or substance abuse? Presumably, HCWs performing far below the standard level of care will be reported within their institution or to their governing body enough times that corrective action will be taken, but what about the majority of HCWs who perform slightly below optimal performance? Like the discrimination argument, the potential harm to patients must be weighed against the invasion of the HCW's privacy and the resulting consequences to his/her practice.

The legal precedents here do not bode well for infected HCWs wishing to keep their privacy. In a 1992 New Jersey case, Behringer Estate $v$ Princeton Medical Center, a plastic surgeon with AIDS brought suit against the hospital for invasion of privacy and breach of confidentiality $[3,27]$. The hospital was informing patients of his illness, and as a result his practice declined. The surgeon argued the risk of transmission was too remote to be disclosed and that the physical condition of the physician did not need to be disclosed under the law of informed consent. The court ruled in favour of the hospital, stating "physicians performing invasive procedures should not knowingly place a patient at risk because of the physician's physical condition"[27]. The court stated

"a reasonably prudent patient would find information that his physician is infected with HIV material to his decision to consent to a seriously invasive procedure because the potential harm is severe and the risk, while low, is not negligible. Moreover, he can avoid the risk entirely without any adverse consequences for his health: by choosing another equally competent physician (where available) he can obtain all the therapeutic benefits without the risk of contracting HIV from his physician. The patient, then can demonstrate not only that the information is material to his decision, but that he would have made a different decision had he been given the facts" [28].

In summary, there seem to be sufficient legal precedents in favour of disclosing the serological status of an infected HCW as part of informed consent for an invasive procedure. Perhaps there is some line that needs to be drawn in terms of what personal information about the physician can be protected from patients, but if it has any bearing on patient safety the courts will likely rule in favour of the patients, as they have in every case to date.
The only other form of legal protection would have to come from statutory law, and it is difficult to foresee this as a priority for legislators.

In ethical terms, it may be helpful to distinguish between restrictions on an infected HCW's practice which are unfortunate vs those which are unfair. It would certainly be considered unfortunate if a surgeon's vision was damaged such that his/her operative complication rate went up dramatically. Would it be considered unfair if this surgeon's operating privileges were taken away? It would be unfair if one surgeon's privileges were taken away for this reason and another surgeon's privileges were unchanged. The type of fairness being considered falls under the theoretical term "formal" justice, and involves treating like cases alike and treating different cases differently [25]. The other type of fairness or justice that should be considered is distributive justice, which involves distributing the benefits and burdens of a policy or decision equally among the different groups involved. It certainly is unfair if infected HCWs bear all the burdens of what is a public health problem, but we argue that this unfairness is best remedied through compensatory measures, i.e. retraining and/or financial compensation, rather than putting patients at risk. Accordingly, the recommendations we propose below allow for an infected $\mathrm{HCW}$ to continue to practise invasive procedures on susceptible patients only if he/she is willing to disclose his/ her seropositivity. If privacy is more important to the $\mathrm{HCW}$, then he/she should be given retraining and financial compensation opportunities. We should also remember that many HCWs have disability insurance plans of some kind which are designed to make up a percentage of the lost income due to health reasons. However, there are many HCWs, particularly physicians, who do not have coverage, and not all plans will provide compensation for entities such as HBV infection.

\section{Systemic effects of disclosure vs non-disclosure}

There are several utilitarian arguments to be made in favour of non-disclosure. Daniels argues "we get better protection against HIV transmission by emphasizing infection controls than we do by isolating and switching from, or restricting the practice of, HIV-infected surgeons and other health care workers [5]." He argues resources are more effectively utilized in the areas of general infection control measures and epidemiological research.

Daniels' arguments in this regard are very compelling. Certainly measures taken to screen for and restrict the practices of infected HCWs should not be at the expense of education, improvements in infection control, and epidemiological research. However, we know how much the courts favour disclosure, thus we are obliged to con- 
sider the time and resources which would be lost in legal disputes if disclosure did not occur. As well, it may be practically difficult for a HCW to have imposed practice restrictions and for them not to disclose to patients and co-workers the reason for the restrictions. The resulting rumours may end up being worse than the reality.

There are other systemic implications to be considered, in particular, interference in the delivery of services. Since risks to HCWs of contracting a blood-borne pathogen are higher than the risks to patients, more HCWs may refuse to treat sero-positive patients $[5,7]$. They may demand that patients be screened for blood-borne pathogens and risk factors prior to performing invasive procedures [5]. HCWs may also be less willing to undergo serological testing if they fear the consequences of a positive result [26].

The current climate of uncertainty as to what happens to HCWs who are discovered to be HBsAg-positive undoubtedly contributes to the fear that HCWs who perform invasive procedures must feel. The prospect of having one's entire career and livelihood decided by an "expert panel" with few governing guidelines is certainly worthy of fear. If the guidelines were more directive and allowed HCWs more opportunity to practice under conditions which did not represent unacceptable compromises for patients, this would likely relieve some of the fear and anxiety amongst HCWs who perform invasive procedures.

In summary, it is hard to clearly favour any policy approach over another in terms of utilizing the least resources or causing the least interference in the delivery of health care services.

\section{What about retrospective disclosure?}

A recent survey of patients in Scotland who had been informed by letter of their exposure to a HBeAg positive dentist provides support for retrospective disclosure of exposure to a newly-discovered seropositive HCW [4]. The survey was mailed to a random sample of 528 patients representing $10 \%$ of the patients in 3 of the 4 health board areas, and 291 (55\%) responses were received. Ninety-three percent of respondents to this survey felt that patients should always be informed if they have been treated by an infectious health care worker, even if the risk was very small. Sixty-one percent of respondents agreed they should have been informed by letter, whereas $29 \%$ preferred to be informed in person.

In the discussion, Blatchford et al. refer to the Association for Practitioners in Infection Control (APIC) rationale for recommending retrospective patient notification [29]. They state three purposes behind such exercises:
"1. It may enable patients infected by disease transmitted from the health care worker to be identified.

2. Exposed patients may be offered a prophylactic medical intervention to reduce their risk of subsequently developing the disease.

3. Epidemiological studies to define the risk of transmission of disease from health care workers to patients may be undertaken."

Blatchford et al. point out a deficit in the APIC statement in that it does not consider the patient's right to information as rationale for doing retrospective notification.

Although the patients can no longer make a decision about undergoing the procedure performed by the infected HCW, because this has already occurred, the information is important to them for making informed decisions about the rest of their lives. They will need this information to get the necessary screening to see if transmission has occurred and follow-up to avoid complications if transmission has occurred. They should also be educated about their risk of transmitting the infection to others and associated prevention measures.

Arguments against retrospective notification of patients are the time and costs involved, and the creation of undue anxiety, as only a small minority of patients notified will have contracted the infection. However, if the patients discovered at a later date that they had been exposed and not notified of the exposure, this would certainly have deleterious consequences with regard to their trust in the health care professions and the patientHCW relationship.

\section{Recommendations for restricting the practice of $\mathrm{HBV}$-in- fected HCWs}

What we propose below is a set of recommendations to be considered by governing bodies when making decisions about restricting the practice of HBV-infected HCWs. These recommendations take into account the relatively high transmissibility of $\mathrm{HBV}$, the available means of preventing HBV transmission, and the legal and ethical arguments in favour of disclosure to patients of transmission risks, including the elevated risks if an involved HCW is known to be seropositive. The recommendations do not mandate disclosure or non-disclosure, but offer infected HCWs further opportunities to practise invasive procedures without jeopardizing patient safety and autonomy if they are willing to relinquish some privacy and reveal their seropositive status.

1. All patients undergoing exposure-prone procedures should be informed of the risk of acquiring a blood-borne 
pathogen such as HBV during the procedure, regardless of their HBV status. This should be disclosed as part of the general pre-operative consent process, along with other routine risks such as hemorrhage, wound infection, and anaesthetic risks.

2. All patients undergoing exposure-prone procedures should be asked for documentation of a complete immunization series or of positive HBsAg serology if previously performed. Patients with no such documentation should be tested for protective antibodies as part of the pre-operative workup. Patients who are not immune should be offered the option of vaccination prior to undergoing an elective or non-urgent procedure.

3. Physicians (or other HCWs) with known HBsAg seropositivity (regardless of their HBeAg status) should be allowed to perform exposure-prone procedures on patients with documented immunity to HBV, either from previous infection or from immunization. They need not disclose their seropositivity to these patients, as the transmission risk is no longer an issue.

4. HBV-seropositive HCWs may perform an exposureprone procedure on a patient who is not immune to HBV provided the patient is a) informed of the elevated risk of infection during the procedure due to the HCW's known seropositivity, b) offered the services of a replacement seronegative HCW to perform the procedure, and c) after considering these options, the patient chooses to have the procedure performed by the infected HCW.

5. When an HCW is discovered to test positive for HBsAg, all patients who underwent exposure-prone procedures performed by the HCW should be traced and notified of their now elevated risk of having contracted HBV during the procedure. They should be offered serological testing and counselling. This process should be a public health responsibility, and not the responsibility of the infected HCW.

It should be noted that these recommendations may not be practical for student HCWs who are HBV seropositive. It will be more difficult for these to keep their seropositivity confidential as they rotate frequently through different services. A large number of people would need to know the practice restrictions which apply to them in order to avoid putting non-immune patients at risk of contracting HBV. As well, disclosure opportunities to patients would be more difficult, since students are often requested to assist in procedures with minimal advance notice, and students do not have the same type of relationship with patients as staff HCWs.

\section{Summary}

Hepatitis B vims is unique amongst transmissible pathogens due to its high transmissibility and its preventability, and therefore ethically and legally acceptable practice restrictions for HBV-infected HCWs are not necessarily equivalent to those for HIV- or HCV-infected physicians. Policy regarding practice restriction of HBV-infected HCWs should take into account the interests of patients, HCWs and the implications of any policy to the health care system at large. The current policy in Canada leaves too much discretion in the hands of vaguely defined expert panels, and is likely contributing to fear and anxiety amongst HCWs who are at risk of acquiring and transmitting infectious pathogens. Providing vaccination against $\mathrm{HBV}$ to patients undergoing elective procedures reduces transmission risks and complements existing vaccination programs. Allowing $\mathrm{HBsAg}$-positive $\mathrm{HCWs}$ to practise without restrictions on patients who have already been infected with or vaccinated against HBVwould allow these HCWs to continue their career with minimal interference. This also avoids undue discrimination against these HCWs. The option for these HCWs to disclose their seropositivity to susceptible patients provides an opportunity for patients to choose what risks they are willing to accept in the course of their health care, for HCWs to educate their patients about infectious diseases such as HBV, and for infected HCWs to perform more exposure-prone procedures. Retraining and financial compensation should be available for those HCWs who choose not to disclose.

\section{Competing Interests}

None declared

\section{Acknowledgements}

The authors would like to thank Shari Gruman for help in preparing the manuscript. Dr Upshur is supported by a research scholarship from the Department of Family and Community Medicine, University of Toronto and a New Investigator Award from the Canadian Institutes of Health Research.

\section{References}

I. Gostin LO: A proposed national policy on health care workers living with HIVIAIDS and other blood-borne pathogens. JAMA 2000, 284: 1965-2970

2. Ristinen E, Mamtani R: Ethics of transmission of hepatitis B virus by health-care workers. Lancet 1998, 352:138I-1 383

3. Tereskerz PM, Pearson RD, Jagger J: Infected physicians and invasive procedures: national policy and legal reality. Milbank $Q$ 1999, 77:5।I-529

4. Blatchford O, O'Brien S], Blatchford M, Taylor A: Infectious health care workers: should patients be told? J Med Ethics 2000, 26:2733

5. Daniels N: Seeking Fair Treatment: From the AIDS Epidemic to National Health Care Reform. New York: Oxford University Press; 1995

6. Murphy T: Health care workers with HIV and a patient's right to know. J Med Phil 1994, 19:553-569

7. Flanagan W: AIDS-related risks in the health care setting: HIV testing of health care workers and patients. Queen's Law Journal 1993, 18:71-128 
8. Logan MK: Who's afraid of whom? Courts require HIV-infected doctors to obtain informed consent of patients. DePaul Law Review 1995, 44:483-5II

9. De Ville KA: Nothing to fear but fear itself: HIV-infected physicians and the law of informed consent. J Law Med Ethics 1994, 22:163-175

10. Karrel Al: HIV-infected physicians: how best to protect the public? CMAJ 1995, I 52:1059-1062

II. Hoey J: When the physician is the vector [editorial]. CMA] 1998, 159:45-46

12. Glantz LH, Mariner WK, Annas G]: Risky business: setting public health policy for HIV-infected health care professionals. Milbank $Q$ 1992, 70:43-79

13. Gostin L: The HIV-infected health care professional: public policy, discrimination, and patient safety. Law Med Health Care 1990, 1 8:303-310

14. Barnes M, Rango NA, Burke GR, Chiarello L: The HIV-infected health care professional: employment policies and public health. Law Med Health Care 1990, I 8:31 I-330

15. Lo B, Steinbrook R: Health care workers infected with the human immunodeficiency virus: the next steps. JAMA 1992, 267: $1100-1105$

16. Mahoney F): Update on diagnosis, management, and prevention of hepatitis B virus infection. Clin Microbiol Rev 1999, I 2:35 I366

17. Proceedings of the Consensus Conference on Infected Health Care Workers: Risk for Transmission of Bloodborne Pathogens. In: Laboratory Centre for Disease Control, Health Canada; 1998

18. Transmission of hepatitis $B$ to patients from four infected surgeons without hepatitis B e antigen. The Incident Investigation Teams and others. New England Journal of Medicine 1997, 336:178-184

19. McQuillan GM, Coleman PJ, Kruszon-Moran D, Moyer LA, Lambert SB, Margolis HS: Prevalence of hepatitis B virus infection in the United States:The National Health and Nutrition Examination Surveys, 1976 through I 994. Am J Public Health I999, 89: I418

20. Lemon S, Thomas D: Vaccines to prevent viral hepatitis. N Eng J Med 1997, 336:196-204

21. Bain VG, Ma M: Acute viral hepatitis. In: First principles of gastroenterology, the basis of disease and an approach to management Edited by Thomson ABR, Shaffer EA. pp. 479-492. Edmonton: Canadian Association of Gastroenterology; 1997479-492

22. Anonymous: Prevention of transmission of hepatitis B. CMAJ 1998, 1 59:71-76

23. From the Centers for Disease Control: recommendations for preventing transmission of human immunodeficiency virus, hepatitis $B$ virus to patients during exposure-prone invasive procedures. JAMA I99I, 266:77|-776

24. Picard $E$, Robertson G: Legal liability of doctors and hospitals in Canada, 3rd Edition edn. Scarborough: Carswell; 1996

25. Beauchamp TL, Childress JF: Principles of Biomedical Ethics, Fourth edn. New York: Oxford University Press; 1994

26. Pinching AJ: Commentary. Infectious health care workers: should patients be told? J Med Ethics 2000, 26:34-36

27. Slovenko R: Informed consent: information about the physician. Medicine and Law 1994, 13:467-472

28. Behringer Estate v. Princeton Medical Center. In: A. 2d, vol. 592. pp. I25 I: N.J. Superior Court; 199II25।

29. ABPC: The APIC statement on purposes for and elements of patient notification programs related to the health care worker infected with the human immunodeficiency virus or the hepatitis B "e" antigen. American Journal of Infection Control 1991, 19:30A-33A
Publish with BiolMed Central and every scientist can read your work free of charge

"BioMedcentral will be the most significant development for disseminating the results of biomedical research in our lifetime." Paul Nurse, Director-General, Imperial Cancer Research Fund

Publish with BMC and your research papers will be:

- available free of charge to the entire biomedical community

- peer reviewed and published immediately upon acceptance

- cited in PubMed and archived on PubMed Central

- yours - you keep the copyright

Submit your manuscript here:

http://www.biomedcentral.com/manuscript/
BioMedcentral.com editorial@biomedcentral.com 